Max-Planck-Institut für demografische Forschung

Max Planck Institute for Demographic Research

Doberaner Strasse 114 - D-18057 Rostock - GERMANY

Tel +49 (0) 3812081 - 0; Fax +49 (0) 3812081 - 202;

http://www.demogr.mpg.de

MPIDR WORKING PAPER WP 2002-050

OCTOBER 2002

\title{
Lowest low fertility in an urban context. When migration plays a key role
}

Francesca Michielin (mika@stat.unipd.it)

This working paper has been approved for release by: Jan M. Hoem (hoem@demogr.mpg.de)

Head of the Laboratory of Contemporary European Fertility and Family Dynamics.

(C) Copyright is held by the authors.

Working papers of the Max Planck Institute for Demographic Research receive only limited review.

Views or opinions expressed in working papers are attributable to the authors and do not necessarily reflect those of the Institute. 


\title{
Lowest low fertility in an urban context. When migration plays a key role.
}

\author{
Francesca Michielin \\ mika@stat.unipd.it \\ Dipartimento di Scienze Statistiche \\ Via Cesare Battisti, 241/243 \\ 35121 Padova - Italy
}

\begin{abstract}
:
In countries with so-called "lowest-low" fertility, the lowest fertility levels are seen in the cities. The main reasons for this development is the difference in the cost of living expenses, combined with income constraints in cities, as compared to these same aspects in rural areas. If we focus our attention on the center of an urban area, migration needs to be taken into account, since it can contribute to particularly low yield fertility.

In this paper we use the Turin Longitudinal Study, which has data on all people who have ever been residents in Turin (Italy) during the period 1971-2001. We study the interdependencies between fertility and out-migration choices for a selected group, from the 1956 birth-cohort. In order to fully understand fertility, we need to consider how fertility acts on out-migration choices. Our findings underline the important role of economic resources and life cycle events in such a context which seem to guide both fertility and migration behaviors. Moreover, while having a child significantly hampers long-distance migration, it also has a lower impact on short-distant moves.
\end{abstract}

\section{Introduction}

Levels of fertility contribute to determine the age structure of the population. If these levels are consistently low, we may need to consider the consequences of low fertility an issue. As an example, Bongaarts and Feeney (1998) assert that "declining 
population size would be salutary from some points of view, but rapid population aging is likely to pose profound social and economic problems.” The issue, therefore, emerges when lowest-low fertility settles as a new phenomenon. During the 90s, an increasing number of countries experienced a lasting drop of the period total fertility rate (TFR) below 1.3, following the leaders Italy and Spain. This new phenomenon is likely to spread to many other countries. In Europe and East Asia, 14 countries presently belong to the group of lowest-low fertility countries, and in the following decade, the latter is likely to continue to grow. Shifting from observation to explanation, demographers first pointed out the new situation, and then tried to develop a general theoretical framework in order to explain and predict future trends (see Kohler et al., 2001).

In this paper, we focus our attention on the urban context in a lowest-low fertility country (here represented by the municipality of Turin, the inner city of an important metropolitan area), in which fertility choices seem to be harder than in other cases. Also, in the past, the urban context was peculiar, since as Kohler et al. (2001) reported, urban areas such as Vienna, Stockholm and Berlin were indeed the first locations that experienced lowest-low fertility levels. This had been a long time before national fertility levels fell below the 1.3 threshold (i.e. in the $30 \mathrm{~s}$ ). Nowadays, if we compare the Italian TFR with the one of urbanities (such as, for example, Turin, Milan, Udine and Florence), we find that a lower TFR is always associated with the cities (see Ongaro, 2002). For example, while the Italian TFR for the year 2000 is above 1.2 , the levels for the above mentioned cities are always between 1.0 and $1.1^{1}$. Numerous studies have dealt with urban fertility, mainly focusing on urbanization processes in developing countries (in 1975 Zarate and de Zarate had already published 
a review article trying to reconcile findings on this topic), while others considered differentials between metropolitan and non metropolitan areas in developed countries (see i.e. Courgeau, 1989). In general, it is well known that urbanization and industrialization have produced many benefits for families and societies, and at the same time they have exerted pressures on the family (see United Nations, 1980). In an urban context, women, for example, are more likely to participate in the labor market, and their role within the family changes. More generally, urban environments and labor markets make it harder to have large families, due to their differences in the cost of living expenses, combined with income constraints, as compared to these same aspects in rural areas (Stark, 1991).

Beyond these considerations, a further important element to consider is the impact of the evolution from city to metropolis. As Martinotti (1993) underlined, in fact, many changes on the morphology of the major cities of Europe occurred over the past previous decades, following the pioneer experience of the United States (Bogue, 1955; Frey and Speare, 1992). After a period of fast urbanization (which in Italy started during the 50s and ended in the mid-70s), the growth levels for the largest cities began slowing down. The new phenomenon has been called counter urbanization (Berry, 1976) or de-urbanization, prefiguring in both cases the crisis (and even death) of the city. In reality, the urban area expanded outside the city, and people began choosing to live in the suburbs instead of the crowded, relatively expensive and polluted center. In other words, the spatial definition of the urban area has changed, also favored by the improvement in transportation for passengers and goods, which in turn allowed decentralization (Yapa et al., 1971). Indeed, extended opportunities of

\footnotetext{
${ }^{1}$ Looking at cohort fertility measures, we can notice how the 1956 birth cohort shows indeed a level of 1.50 in Turin municipality, which compared to Italian level (1.75), is significantly lower (although both values are under the substitution level).
} 
commuting decrease the need of coincidence between the place of work and the place of residence, leading to possible spatial separation of these two life-domains.

As a metropolitan area, Turin also experienced these phases. Turin, together with Genoa and Milan, is one of the cities in the "industrial triangle", the major industrial area in northwestern Italy (Bonifazi and Heins, 2000). Its development was mainly linked to the evolution of the Fiat car industry, which attracted consistent flows of immigrants during its economic growth. The population of Turin municipality, for example, which was approximately 700 thousand people in 1951, reached 1,100 thousand at the beginning of the 60s. After this phase, since the mid 60s, the central area began to be characterized by lower (but still positive) net migration flows, while the areas which gained more population are the outlying districts or urban ring areas. Only during the early 70s did the trend change, showing negative net flows for Turin municipality and only slightly positive net flows for the suburbs (IRES, 1994). At the beginning of 2001, the population of Turin city was approximately 900 thousand, which corresponds to more than half of the population of Turin's entire metropolitan area (consisting of about 1.6 million), and to two fifths of the province (2.2 millions). Studying urban fertility in Northern Italy is therefore particularly appealing, since we deal with the context of lowest fertility in a country of lowest low fertility. The aim of the present article is to analyze fertility levels in the urban context of Turin municipality, i.e. in the center of a relatively large metropolis, as well as observing how out-migration choices can be related to fertility behavior and controlling for possible endogeneity of the process of urban fertility on out-migration. Primarily, if we want to understand fertility behavior in the center of an urban context, we also need to consider the fact that out-migration can be motivated by the current household 
situation, and also by desired fertility. Both processes need to be taken into account simultaneously.

The paper is structured as follows: in Section 2, we underline the reciprocal impact of migration on fertility and vice-versa, and look at possible common factors which influence both decisions. Section 3 contains a description of the data and the types of models that will be used, while in Section 4, we discuss our main findings, followed by Section 5 , where we present our concluding remarks.

\section{Migration and fertility as (potentially) interrelated processes}

The study of the interrelationship between fertility and the migration process has mainly focused on two different perspectives. On the one hand, researchers have been particularly interested in the impact of migration on fertility, studying the fertility of immigrants, while on the other hand, current parity and anticipated fertility were considered among the critical determinants for the decision to move.

\section{1 (Im)migration and fertility}

Concerning the behavior of immigrants, the literature has focused on testing some basic hypotheses which could give some light toward the mechanism that links fertility before and after migration. The major hypotheses were adaptation, disruption and selection. These hypotheses describe different situations. First, adaptation (Goldstein and Goldstein, 1983; Stephen and Bean, 1992) predicts a gradual assimilation to fertility norms and behavior of the host society. Second, disruption considers only a temporary effect of migration, which depresses fertility in the first period after the move, because of spousal separation or the settling-in process (Carlson, 1985). Finally, selection (Hervitz, 1985 and Kahn, 1994) deems that migrants are selected through socioeconomic characteristics, which in turn influence 
also fertility behavior: controlling for these characteristics, no difference is expected between migrants and non-migrants.

The literature has mainly tested these three hypotheses with respect to the urbanization process itself, both in developing and industrialized countries, focusing on urban and rural differentials. In addition, some studies have focused on multicultural countries, such as the United States and Australia, where consistent international migration flows contribute to define the overall fertility levels. For instance, Ware (1975), Carlson (1985) and Abbasi-Shavazi and McDonald (2000, forthcoming) studied fertility behavior of Australian immigrants; Ford (1990), Stephen and Bean (1992) and Kahn (1994) focused their attention on the United States; Hervitz (1985) on Brazil. Goldstein (1973) and Zarate and de Zarate (1975) on the urbanization process in developing countries.

In the context of lowest-low fertility, the analysis of the fertility of immigrants can be of major interest. This analysis allows for an understanding of the impact of immigrants' fertility on the overall national level ${ }^{2}$. It considers how different fertility models are (or are not any longer) applied when the external conditions change due to migration (and therefore to weight the importance of external conditions), in addition to controlling for a source of population heterogeneity in fertility behavior.

\subsection{Fertility and (out)migration}

In the literature concerning migration, particular emphasis has been given to life-cycle events as possible determinants of the decision to move (Courgeau, 1984). This follows the pioneering idea expressed by Lee (1966), that migration can be considered as an instrumental behavior for achieving specific goals in some other parallel career. 
In this respect, the "household career" acts as a push and pull factor for the decision to move. The household career can, on the one hand, define constraints for the move, being then a conditioning career (Mulder, 1993). Long (1972) demonstrated that married couples without children are more geographically mobile than married couples with children, where mobility is even more restricted during school ages. Children create ties with current location and within the members of the family itself, and this can hamper migration. If a family has to move, the net family gain will be evaluated, instead of personal gain (Mincer, 1978).

On the other hand, the need to adjust housing to changes in the household composition is an important source of mobility (Grundy, 1986, Baizan, 2002), and residential mobility can thus be a possible response to fertility.

The latter push factor can then be very strong in the core center of an urban area, where spacious single family dwelling units are not easily available, and, when available, present very high costs in comparison to their quality. Internal dynamics of the city, in this respect, play an important role. A process of "gentrification" (that means reevaluation of some part of the city, shifting from a low-income area to a middle-class area) further increases the costs of a home in a specific zone, and tenure is even more difficult (Zukin, 1987). Moreover, related to expansion of the urban service economy, some residential buildings have been converted to service use, resulting in lower availability of dwellings, with higher prices.

\subsection{Factors that may simultaneously influence both fertility and (out)migration}

Besides the direct effects of fertility on migration decisions, we also need to take into account some unobserved factors that could potentially influence both processes at the

\footnotetext{
${ }^{2}$ To this regard, Ongaro (2001) states, for instance, that in recent years the period TFR increased slightly, and that it is important to understand that this increase is due to immigrants, which is a growing component.
} 
same time. Speare (1974) and Landale and Guest (1985) show, for instance, that residential preferences may play an important role. According to Mulder and Hoomeijer (1999), the importance of the residential environment increases according to the rising size of the family, since married couples, and in particular those with children, invest financially more and more in the family. Therefore, the quality of the dwelling and its environment has to be high, and for the same reason, ownership is preferred to renting.

Rather than minimal requirements for health and safety, preferences reflect the existence of some commonly held norms. Housing norms, for example, prescribe that housing should be owned by the occupants, be of an independent structure, have sufficient outdoor and indoor space, given the age and sex composition of the family (Morris et al., 1976; McAuley and Nutty, 1982). Cultural and family sequential norms require, moreover, to reach residential stability before having children (Baizan, 2002). All of these elements discourage family formation in the central city, which remains generally the preferred location among young singles and couples with no children, but looses attractiveness during family formation, childbearing and child rearing lifestyle stages. Many researchers in the United States believe that housing market conditions, high levels of crime and segregation, all contribute to outflows from the central city of important metropolitan areas. This is especially so for families rather than for single persons (Frey and Kobrin, 1982; South and Crowder, 1997), assessing that the central city does not fit family formation stages. Despite the fact that American cities are extremely different from European ones, this gives support to the fact that migration can become a possible strategy for those who desire or intend to have children. At the same time, "a reluctance or inability to move to larger accommodations may, in some circumstances, depress fertility, and the availability of 
housing may affect any relationship between mobility and fertility" (Grundy, 1986). It is well known that "changes in residence represent endogenous determinants in an interdependent system of demographic relevant processes" (Flothmann, 1993), but we focus here only on the interrelationship between migration and fertility.

In other words, the decision to migrate becomes part of the strategy leading to having children. This means that moves are not only influenced by current household situations, but also by individual desires for children and by the importance attached to cultural and social norms. This includes the perception of norms as a source of heterogeneity of the population, as reflected by the idea of familism as a possible determinant of intra-metropolitan residential mobility (Sabagh et al. 1969): basically, family-oriented households would be more likely to search for locations suitable for child welfare and family living than those households who are not ${ }^{3}$.

The main question we would like to answer is, therefore, if in the particular case of a central city, these processes are really interrelated, and in what way. With this aim in mind, some characteristics of data and methods will be presented.

\section{Data and methods}

The Turin Longitudinal Study (TLS) is a longitudinal database, which consists of register data linked to 1971,1981 and 1991 census data, used extensively for epidemiological purposes (Costa and Demaria, 1988; Costa et al., 1994), and in a limited way, with socio-demographic purposes (Billari et al., 1999). The data set covers the entire period starting from 1971 (year in which register has been computerized) to the end of 2000 . Therefore, we have information towards all people who have ever resided in Turin municipality since 1971. Being an exhaustive source, 
the TLS allows us to consider fertility and migration behavior for the entire population we are interested in, without problems linked to sample selection.

For the present study, we focus our attention on women born in 1955 and 1956, for whom we can follow the whole reproductive period (at the beginning of the 70s they were 15 years old, while $44-45$ in 2000). Since our main goal is to study urban fertility and to concentrate on the impact of forming a family and having children on migration behavior, we have then selected only women who resided in Turin municipality, at least since their $15^{\text {th }}$ birthday. In this way we assure that at the (theoretic) beginning of the reproductive period, all the women are already in Turin, and therefore fertility choices are directly influenced only by the urban context (as well as searching for a mate, finding a job, or in general adult behaviors). Immigrants can then be considered homogeneous in respect to the life-cycle stage during which immigration occurred, since this took place for everyone, during childhood. In this way we avoid lack of control for the interrelation between immigration and family formation (see Andersson, 2001). In our study the effect of being immigrant acts only through the different cultural background.

For these women we focus attention on the period following marriage, explicitly selecting people who lived at least until marriage, in Turin, so that changes in this choice are only due to a change in marital status and household situation. Considering the peculiarity of the Italian situation, this allows us to catch their entire fertility history. Since fertility in Italy is almost completely marital (Castiglioni and Dalla Zuanna, 1994 and Billari et al., forthcoming), we can deal with the first trigger for migration: marriage and leaving parental home happen usually simultaneously in Italy (Billari, 2001) ${ }^{4}$. The final data set consists of 7,623 women.

\footnotetext{
${ }^{4}$ Moreover, since we are analysing data coming basically from Turin register that allows us to have information on the period until out-migration occurs, we would lack controlling all marriage out-
} 
For all women, we have information both on migration and on fertility history until censoring (which corresponds to death, out-migration or the end of 2000). It is possible to reconstruct fertility history until censoring happens, by linking each person to his/her parents, and using both register and census information. As shown in Fig. 1, out-migration leads automatically to the censoring of the observation, and since we hypothesize that the two processes are linked, the censoring event is supposed to be correlated with the phenomenon under study.

A possible solution for taking this issue into account, and the existence of heterogeneity factors in the analyses, is to use a structural equation for event history models. This allows us to simultaneously consider more equations, including in each some unobserved component that in principle can also be correlated (see for example Lillard, 1993; Lillard and Waite, 1993 and Lillard and Panis, 2000).

Since we study two processes (fertility and out-migration) we will use two simultaneous equations. The first equation will describe fertility, the second one migration. Fertility can be considered as a process with repeated events, and the "baseline hazard" (which describes the hazard depending on the duration of the exposure) can also be particularized for each order of births. For out-migration, instead, we observe only one spell. We will describe each equation in more detail later.

In general, we model the logarithm of the hazard rate as follows:

$$
\ln h(t)=y(t)+\sum_{k} z_{k}\left(u_{k}+t\right)+\sum_{j} a_{j} x_{j}+\sum_{i} b_{i} w_{i}(t)+\varepsilon
$$

where $y(t)$ is a linear spline which describes how the logarithm of the risk, according to the duration of the exposure, each $z_{k}\left(u_{k}+t\right)$ represents via spline the dependence 
on another dimension of time (as for example the current age of the woman), whose value can be completely predicted since their value at the beginning of the exposure $\left(u_{k}\right)$ is known. Using a linear spline to describe the time dependence is particularly flexible, since entirely different shapes can be represented with the same parametric function ${ }^{5}$.

Moreover, we consider also other time constant $\left(x_{j}\right)$ and time varying covariates $\left(w_{i}(t)\right)$ whose effect is to shift proportionally the baseline hazard.

The final component $\varepsilon$ denotes an unobserved component, which is constant over time, and specific for each unit. If we assign $\varepsilon^{p}$ and $\varepsilon^{q}$ to the two components for the processes $p$ and $q$, we can write their joint distribution, assumed to follow a bi-variate normal distribution:

$$
\left(\begin{array}{l}
\varepsilon^{p} \\
\varepsilon^{q}
\end{array}\right) \sim N\left(\left(\begin{array}{l}
0 \\
0
\end{array}\right),\left(\begin{array}{cc}
\sigma_{p}^{2} & \sigma_{p q} \\
\sigma_{p q} & \sigma_{q}^{2}
\end{array}\right)\right) .
$$

Both the variances $\left(\sigma_{p}^{2}, \sigma_{q}^{2}\right)$ and the correlation between heterogeneity terms $\left(\rho_{p q}\right.$, which follows from the covariance) are estimated by the model.

This particular way of describing each process allows the inclusion of unobserved factors, influencing fertility, and others that affect the probability of migrating. Concerning migration, the idea of the existence of heterogeneity between individuals is not new. In 1955, for example, Blumen, Kogan and McCarthy developed the mover-stayer model (Blumen et al., 1955), in which the population was ideally divided in two groups (choice that allowed to keep the problem mathematically tractable), representing who remains permanently in their state of origin, and who

\footnotetext{
5 "Define a spline" means to fix some knots, while the shape is estimated supposing a linear trend between knots.
} 
moves during life. Later on, extensions considered different (even continuous) heterogeneity distribution (e.g. Spielerman, 1972; Davies et al., 1982).

Many scholars pointed out the existence of unobserved heterogeneity, also in the fertility process (Gini, 1924; Heckman and Walker, 1992). In general, it is supposed that differences among women in unobserved fecundity result in unobserved heterogeneity, which in turn represents a degree in propensity of women in having children. In modern societies, where fertility is perceived as a real choice, we can think about people's attitudes toward the family, i.e. the amount to which people are actually family-oriented.

We return again to the idea of familism, associated now with fertility behavior (for a discussion on perverse effects of familistic norms in the Italian case, see Dalla Zuanna, 2001). In the present article, however, we are dealing with urban fertility, and therefore we have to consider the meaning of 'unobserved' in this peculiar context (heterogeneity does not directly describe a lower or higher propensity of having children in general, but of having children in Turin municipality). Allowing the presence of potentially correlated unobserved heterogeneity, we check whether endogeneity also acts via these components.

A positive correlation would in fact mean that, conditionally to the observed characteristics, women who have a propensity of bearing more children also have a higher propensity to migrate. On the other hand, those who have a lesser interest to move will also have a lower propensity on having children. If we can interpret heterogeneity in the fertility process as a measure of the amount to which people are actually family-oriented, we would say that more family-oriented people would easily leave the city than less family-oriented people, according to Mulder's interpretation (1993). In this case, the positive effect of fertility on migration acts also through the 
unobserved components, in such a way that whoever desires more children is also more prone to leave the city.

Similarly, a negative correlation would mean that if we consider two women with the same observed characteristics, the one with a higher propensity to have children would also prefer to stay longer in Turin. On the contrary, people who would prefer to migrate would also be less prone to bear children. In this case, strength is given to the perception on how life is in Turin municipality, or in a specific neighborhood, for each woman (Speare, 1974, underlined how important perception of quality of life is). This also influences fertility behavior (whoever likes the city more, finds it to be a good place for bearing children, while whoever dislike to live in the city depresses his/her fertility, confirming then Grundy's theory, 1986).

Since the estimated correlation coefficient represents only the net impact of these two contrasting forces, a null correlation would mean that these two strengths cancels each other out.

In the following subsections we will describe in more details the equations representing fertility and migration, leaving the description of results for the next section.

\subsection{The equation describing fertility}

Childbirths are repeatable events, but each birth is a step with a more complex strategy. The decision making model to which we refer hypothesizes that women act rationally to realize a plan of desired family size (Becker, 1981). Since different strategies can be compatible with the same number of children, women can choose to act in different ways, and observing how the process evolves can add information on the process as a whole (Yamaguchi and Ferguson, 1995; Rosina, 2001). Therefore, 
when describing fertility, information concerning the past of the process needs to be considered for predicting its future.

The basic event of interest is a new birth. We keep the hazard relative to first parity from transition to higher parities distinct, since the former event represents the entry into motherhood, while, for the others, the fertility process yet began (differently from Yamaguchi and Ferguson, 1995, we consider here also transition to first birth) ${ }^{6}$. Moreover, the first baseline is associated with the length of marriage, and it is possible that a number of marriages happened due to a pregnancy.

Apart from the first child, the length of previous interval gives additional information in the understanding of subsequent fertility. Murphy (1992), for example, includes possible meanings of interval between births: "physiological difficulties in conceiving, continuity in terms of contraceptive usage, possible episodes of spousal separation, low coital frequency, stable attitudes to appropriate birth-interval length, and constraining and socialization factors due to differing educational and employment histories."

As well, in this case, we distinguish the first interval from the subsequent, thinking that a short interval between two births predicts shorter spacing to the next one (see again Yamaguchi, Ferguson, 1995), while the interval between marriage and first birth reflects the choice for entering motherhood. Therefore, if the latter length is very short, as in the case of a pregnancy caused marriage, it is possible that there was no real intention to start the reproductive period, and hence to consciously proceed to higher parity.

\footnotetext{
${ }^{6}$ In the general equation, we build the baseline risk as the risk associated with the duration of the exposure, which starts nine months after the birth of the child of order $\mathrm{j}-1$ for a child of order $\mathrm{j}$, or at time of marriage for the first child. Moreover, since the baseline risk for the first child can not be considered as proportional to the baseline of the risk for children of different orders, we specify two different baselines. The first one is associated to first birth, while the second to all other births (which, in turn, can differ by a proportionality factor).
} 
Moreover, the age of the woman at the beginning of each birth interval can be significant (Marini, 1981). One possible reason is that a woman who started to be at risk (that means who married or had a child of parity $j$ ) at very young ages will have a long time to conceive an additional child. She will also have a higher fecundity, and we can associate a higher probability of progression in the parity. On the other hand, she may decide to postpone the event, since she has more time.

Moreover, in the literature it has been found that if a woman is very young when she starts her family building, she will show shorter intervals between her births and a high level of complete fertility (e.g. Hoem and Hoem, 1989). The latter phenomenon is known as the engine of fertility (Rodriguez et al., 1984), and it can be associated with a strong investment in family formation. This is due to family building that begins at very early ages, or to a conscious will to attain a larger family size by a certain age (in Yamaguchi and Ferguson, 1995).

We model the effect of age at marriage on first birth, as a linear spline with three knots, corresponding to age 20, 23 and 26 . The basic idea is that very early age at marriage is associated with a high probability of conceiving a first child, and then the probability declines (so we expect a negative slope for age 15-20). Age 20, 23 and 26 represent quite defined situations, since around these ages, 25, 50 and 75 per cent of the women under observation are already married, and therefore we can consider the two more extreme groups as people "anticipating" or "delaying" marriage.

For subsequent births, we expect that the effect always follows in the same direction, i.e. that the older the woman, the lower her probability of conceiving a child. The latter effect is expected to be stronger with an increasing order of births, since women who enter the risk of having a high parity at early ages are more selected as "fast movers" (Murphy, 1992) than those who reached low parity. The woman's age at the 
beginning of the exposure of bearing the $j$-th child (i.e. 9 months after the birth of the child of order $j$-1) will therefore be considered as a linear spline, specific for each order of birth.

As a final variable describing previous fertility, we also include the case the last pregnancy have led to twins, because in this case women may have a strong wish to wait for a long time before a new pregnancy (Standberg and Hoem, 2002). Rosenzweig and Wolpin (1980) demonstrated, for example, that having had twins at parity one represents mainly a time shift of subsequent fertility, although this has only negligible impact on completed family size.

All the variables included to this point refer to the past of the fertility process, and their effect is thought to be analogous to other contexts. The following characteristics are particularly important in this specific context. We consider if the woman had immigrated, and we control for educational level, both in interaction with parity.

We expect higher fertility rates for immigrants (since most immigrant women belong to regions in which fertility is higher than in Turin). This effect can be constant in respect to parity (immigrants maintain their fertility preferences also in the new society), or vanish gradually for higher parity (immigrants adapt to the host society).

Concerning the educational level, the result is, in principle, difficult to predict for two reasons. First, the relationship between educational level and fertility is itself quite ambiguous, since it is the result of the balance between opportunity costs of rearing children and the possibility of doing so (Becker, 1981). Women with a high educational level have a higher earning potential in the labor market, which in turn increases the relative costs of children and therefore reduces the demand of children. Moreover, they spend more time in education, and this delays entry into marriage (Blossfeld and Huinink, 1991), although it is not clear whether entry into motherhood 
is affected directly. On the other hand, a high level of education is associated with a high-income level, which defines the economic resources for facing new births. While in the past, opportunity costs of childbearing for women were assumed to more than compensate for the income effect (and the opposite for men). In recent years, a positive effect of a mother's education on fertility was found, at least for high parity. For the first parity, Marini (1984), and Liefbroer and Corijn (1999) demonstrated that both educational attainment and labor force participation have a negative impact on women, which is stronger for entry into motherhood than for entering a union. This suggests incompatibility between having the first child and being employed, or having invested heavily in human capital. Other studies (see for example Hoem and Hoem, 1989 and Kravdal, 1992) pointed out that for the second and the third parity, controlling for other covariates, women who have higher education also have higher relative fertility. The latter effect seems, however, to disappear when the existence of unobserved components is taken into account (Kravdal, 2001).

Beyond these general considerations, we should take into account that in the urban context, the availability of economic resources is more important than elsewhere, and therefore we can expect that a high level of education raises the probability of having an additional child for high parities.

\subsection{The equation describing migration}

We have previously underlined the effect of current parity and desired fertility as a possible reason for migrating. In this context, we would like to concentrate on the effect of demographic variables on migration. In particular, we focus on how migration choices of married couples are related to their fertility. 
The main variables will therefore deal with the household situation. The baseline risk will in fact measure the risk of migrating as a function of marriage duration. The shorter the marriage, the higher the probability of migration, since the new household situation probably altered residential preferences and needs (Mulder, 1993), and since marriage very often coincides, in Italy, with leaving the parental home (Billari, 2001). Delays in registering the residential changes can cause strong dependence with duration of marriage.

Residential adjustment can then be necessary whenever the current location is no longer suitable to family size. According to the number of children, larger families will probably try to find better and cheaper accommodation, and move (Mulder and Hoomeijer, 1999). But if children are in their school age, this increases ties with the current location (Long, 1972).

We control, moreover, for the current age of the woman, that in this case will represent both an adjustment for the selection through age at marriage and the effect of resistance to move, which probably increases with age. Indeed, since we consider the current age of the woman, early ages correspond only to women who married early in their lives. These women can be selected, having few possibilities of moving due to a lack of economic resources. When age increases, its effect is estimated on a less selected group of women, so that we can attribute to age a more general "attrition effect". Landale and Guest (1985), for example, found that controlling for both family life-cycle stages and residential satisfaction, to ages higher than 46 is associated with a low propensity to move.

Apart from the household career, we consider additional information, such as being an immigrant or not, distinguishing then also by the provenience of immigration (Turin county, North-Center Italy or South Italy and foreign countries). In general we 
would expect that previous moves enhance next moves (because less are the ties with Turin municipality), but this may differ by provenience. Moreover, we control for the educational level ${ }^{7}$. The latter variable represents the possibility to move, influencing the extent to which people wanting to move can fulfil their wish, and on the other hand, the possibility to stay. Therefore, its effect is not easily predictable. Moreover, it is related to job position, which can be very important for the analysis of migration behavior (Long, 1974; Da Vanzo, 1981; Sandefur and Scott, 1981).

\section{Results}

Results are shown in Table 1, 2, 3 and 4. In Table 1, we present the parameters for the fertility process, in Table 2 and Table 3 we report the analysis for migration and in Table 4 we consider fertility and migration as interdependent processes, allowing also for correlation between the unobserved components. We consider only three basic models for fertility and for migration: the first one describes each process with limited information, the second includes all observed covariates, while only the third considers the existence of an unobserved heterogeneity component. Regarding the out-migration process, we distinguish by destination of the move, in a competing risk model, for underlining differences on the processes. We comment on these results

\footnotetext{
${ }^{7}$ This variable is not decreasing over time (since only upward levels can be obtained) and it is moreover almost steady after marriage. It is a well-known fact that education is hardly compatible with adult roles, expecially in Italy and Spain, and that both social norms and economic reasons push people to end education before marrying (see for example Blossfeld and Huinink, 1991 for the general idea and Blossfeld and De Rose, 1992 or Coppola, 2002 concerning the Italian case). Selecting the maximum/best educational attainment ever registered in any data source (register or censuses), we will therefore attribute the true educational level obtained before marriage.

It would anyway be interesting to include in migration analysis information toward the occupational status and the working career of both the woman and the man in the couple, but since we expect that changes in jobs, current working positions (or the current working position) and characteristics of the dwelling have a "continuous effect" on determining migration chances and triggers, the available data from censuses are not enough. These data are collected indeed every 10 years, and we have them only if at the time of the census the subjects of study were residing in Turin.
} 
(shown in Table 3), discussing out-migration in general. Finally, both fertility and out-migration processes are considered as a whole system.

\subsection{Fertility}

In discussing results for fertility, we will first focus on the main duration baseline, then discuss how different aspects of the past of the process influence its future, analyze other control variables, and finally, describe the impact of unobserved heterogeneity.

Fig. 2 presents the natural logarithm of the baselines hazards of having a new child, when the risk associated to the first child is hypothesized to be different (not proportional) to other risks, which in turn can be considered proportional to each other $^{8}$. The baseline describing the risk of having a first child after the marriage shows two well-defined situations separated by an intermediate low risk period: pre-marital conceptions and conceptions after marriage.

The other baseline hazard (which represents the risk of having a second birth, and is proportional to the risk of subsequent ones) shows an increasing trend for the first nine months, while afterwards it remains quite stable until the $5^{\text {th }}$ year and subsequently declines. As expected, if we do not include any additional covariate, the higher the parity, the lower the risk of having an additional child. If we in turn consider other information, as for example the age at previous birth or the length of preceding interval, this effect is absorbed.

In general, not only is the number of children important to predict subsequent fertility, but also time spacing between births (Yamaguchi and Ferguson, 1995). We

\footnotetext{
${ }^{8}$ To see if the model with two baselines is preferable to the model with four distinct main hazards, one for each birth order until the $3^{\text {rd }}$, and then one for higher orders, we used the BIC statistic (Raftery, 1995), useful for comparing performance of non-nested models, and this confirmed that the most parsimonious description is preferable.
} 
hypothesized a different effect of the length of the previous interval for the first birth and for subsequent births, distinguishing therefore protogenesic and intergenesic intervals. As expected, if we consider intervals between births, the general effect is that the longer the previous interval, the lower the probability of conceiving a new child. Aside from the protogenesic one, this is true only for intervals longer than 9 months, reflecting that for premarital conceptions, the lower the interval, the lower the probability to conceive again (which is consistent with our hypothesis concerning unintended fertility and with the results on Italy obtained by Rosina, 2001).

Moreover, if the last pregnancy led to twins, the fear of repeating the experience (in terms of time and energy spent with more than one child at the same time) has a negative, although not significant, effect on subsequent fertility.

Another important aspect we included in the analysis consists of the age of the woman at previous child birth or at marriage, considered specifically for each order of birth. According to previous results (see for example Hoem and Hoem, 1989) age at marriage shows how women who marry at very early ages have the highest probability of bearing the first child, while women who marry quite late (at least later than $75 \%$ of the same cohort) also delay motherhood.

For other parities, as expected, the older the woman the lower the probability of bearing a new child, and the effect is stronger for higher parities (as in Murphy, 1992).

The behavior of immigrant women is particularly interesting. At the beginning of their reproductive period, they significantly differ from autoctones, showing higher propensity of bearing a first child, and also a second one. With the increase of parity, they seem to become more similar to Turin's population. These results would support the idea (known in the literature as adaptation hypothesis -see Goldstein and 
Goldstein, 1983 and Bean and Swicegood, 1985) that adaptation to the new economic, social and cultural environments at place of destination, leads also to a change in fertility preferences of migrants (Hervitz, 1985).

Also, the effect of the educational level changes according to parity. A lower probability of conceiving corresponds to the first parity, with a higher educational level. A u-shaped effect emerges for transition to parity two and parity three. Reaching parity four is not dependent on the educational level. This result supports the hypothesis that in the urban area, for proceeding to high parities, it is particularly important to dispose of high levels of resources, and that this is no longer absorbed by the unobserved component (as was in Kravdal, 2001, for Norway). When we add the heterogeneity term, the model in fact improves, but the effect of the covariates does not change, although their relative importance is a little bit higher.

\subsection{Models for out-migration}

Out-migrations from Turin municipality are strongly conditioned by demographic events. In the very first months of marriage, out-migrations occur with the highest probability. According to Grundy and Fox (1985), and Mulder and Wagner (1993), residential adjustment seems, therefore, a consequence of marriage itself. After one year, then, the risk of leaving Turin municipality declines only slightly with the length of marriage (see Fig. 3). This trend is common to both short and long distance moves, but it corresponds more closely to the first kind.

Other demographic events are important determinants. Having one child seems to significantly discourage out-migration, while this is not true any longer for the situation with a higher number of children. When we control for other variables, it seems that the trend, "more children - higher probability of move out" remains. 
Nevertheless, if children are school aged, this creates ties with the place of residence, hampering the possibility of leaving. When we distinguish by destination, the effect of parity differs slightly: the negative impact of parity hampers only long distance migration, and also having school aged children has a stronger negative impact on this destination.

Another element which can discourage mobility is age: after age 40, the probability of moving drops, probably because people have already settled-down (as in Landale and Guest, 1985). A low propensity to move is associated, also, with very young women, but this can be the result of the particular selection we applied. Since, in fact, we considered only married women, when we are considering young women, we are also taking into account early marriages, and therefore scarce economic resources may have been the causes which hampered her mobility. Grundy and Fox (1985) found similar results analyzing the English and Welsh population around 1971.

The idea that economic resources can be very important in an urban context is moreover consistent with the effect of educational attainment: the higher the educational level, the lower the probability to out-migrate. People with a high educational attainment have the higher chances to stay (or at least find a better location in the city that is affordable), and may be more oriented to the "urban culture", while others may be forced to move outside the city to find relatively cheaper accommodations. In this respect, we have to take into account that the women we selected spent at least the entire period between age 15 and marriage in Turin municipality. Therefore, we can suppose they had high incentives to try to stay in the city (due to social capital investments -see i.e. Astone et al., 1999- and ties with the current location). 
Finally, past residential history proves to be important. In comparison to nonimmigrants, immigrants from the North-Center Italy indicate a higher propensity of leaving Turin municipality, while originating from the South hampers migration. The latter result shows that those who come from the South have higher incentives to stay longer. A possible explanation is that difficult life conditions in the place of origin caused the immigration of the family, and returning (or moving again) would mean again, finding an uncertain situation. Moreover, immigrants have lower incentives to move to the northern country side, where they have no family ties, and a return to place of origin would mean affording a "longest-long" distance move. Otherwise, we can also assume that the consistent flows that took place in the 50s and 60s from the southern part of Italy towards Turin set up something like a "southern community", which women leave less often. This latter interpretation is supported also by the fact that coming from the South hampers out-migration to every destination, also to Turin province. On the contrary, belonging to Turin province significantly facilitates returns, and coming from the North or the Center enhances a long distance move.

When we include, in the analysis, the heterogeneity term, the model improves in a statistical sense, although the effect of the covariates does not change. This does not help us in assessing a possible meaning of unobserved component, but a general idea of attachment to the city or perception of the quality of life can be applied.

\subsection{Models for fertility and migration}

Table 4 shows all parameters obtained in the model when we consider fertility and migration as processes linked both through the observed outcome of the parallel process and unobserved components. In this model, we are controlling for possible 
correlation across unobserved factors, controlling therefore for the selectivity of migration on fertility process.

Unobserved factors seem to be only slightly negatively correlated, but the correlation coefficient is not significant. The general idea is, therefore, that factors which are positively correlated almost compensate the ones negatively correlated, and the net effect is only slightly negative. There is therefore only partial support for the hypothesis that the net effect predicts that a woman who shows a higher propensity than another one to have children in Turin, will also probably have a higher wish to stay in Turin's municipality and vice versa. A possible interpretation of this result is, then that unobserved components can in part be an expression of how people perceive quality of life in Turin municipality (or in the specific neighborhood) in each dimension of life. Or, in different words, the way in which people are involved in the life of the city (including also their social capital investments). As Speare (1974) stated, residential satisfaction can have an independent effect on mobility, also when the effects of background variables (such as duration of residence, age of the head of the household, location of the house - city or suburbs, being an owner or a renter, and so on) are taken into account. Following this interpretation, the better you feel in Turin, the more you want to have children there, and the less you desire to move. At the same time, Grundy's theory (1986) that negative housing conditions in the city depress fertility seems to be partially confirmed.

If we examine then, the effect on the other coefficients, we can appreciate that the only interesting change is on the parity coefficient in the migration equation. While before a significantly lower probability to out-migrate was associated to parity one, now there are no longer significant differences with having no children, and the apparent trend (the more children, the higher the probability to move) still remains. 
Therefore, even if we control for correlation across unobserved factors, having children does not seem to hamper migration.

\section{Conclusions}

Using data from the Turin Longitudinal Study, we analyzed urban fertility in Northern Italy. Since data on urban fertility are censored by out-migration, we studied both careers together controlling for the existence of correlated unobserved components, that can bias results. Trying to maximize the impact of demographic events on outmigration choices, we selected people who were resident in the city at least since age 15, studying their behavior after marriage. This particular selection considers people who chose to stay in the city at least until marriage. This means that changes in the decision to stay are with a higher probability related to family life cycle stages.

In this context, fertility seems to be particularly conditioned by the educational level of the woman, which determines more the resources for facing new births than the rising opportunity costs of children (see Becker, 1981). The same covariate is then important also for out-migration, reinforcing the idea that staying and therefore having children in Turin municipality is a matter of possibility.

Moreover, parity seems to have an effect on the choice of moving, leading people with more than two children to consider the decision to move from the city more than people with just one child. When the number of children is high, indeed, the pull factor associated to parity (creating ties with the current location - Long,1972) is compensated by its push factor (Grundy, 1986; Baizan, 2002).

If we now consider the behavior of immigrants (who have been often been held to raise fertility levels in such context), their fertility model is proved to be important, at least for first parities. The supported hypothesis is then adaptation (Goldstein and 
Goldstein, 1983; Bean and Swicegood, 1985), which states that immigrants behave differently from the host society until adaptation to the host urban society occurs.

Including the unobserved component in both processes allowed estimating unbiased coefficients (Lillard, 1993). Unobserved factors which simultaneously favor outmigration and fertility almost compensate the unobserved factors which facilitate one process but hampers the other, and the net effect of these components is only slightly negative, i.e. the correlation across unobserved factors is negative but not significant. The net effect supports the idea that out-migration may be perceived as a possible solution to fertility plans which can not be completely fulfilled in the city. This is in line with findings, assessing that people may adjust the timing of events in the family life course in accordance with the availability of appropriate housing. Murphy and Sullivan (1985), for instance, discussed the connection between home-ownership and family stages in Britain. Mulder and Wagner (2001) focused attention on the Netherlands and West Germany. A growing research interest focuses on the connection between family formation and housing, and this paper places itself in this area.

Our research has a number of limitations. First, we can only consider fertility behavior in Turin, and infer on future behavior (after migration occurs), only analyzing the correlation through the unobserved components. Second, some important information could not be used, as for example, information toward the working career. Finally, we focused on migration behavior of married people, but it would be very interesting to also include unmarried individuals in the analysis. Unfortunately, since after a move from Turin, we do not have any information toward family life cycle stages, we could not control migrations which happened because of 
marriage when the residential change anticipate family formation event, and this led us to select only married people.

\section{Acknowledgements}

I want to thank the Research Group on the Demography of Early Adulthood of the Max Planck Institute for Demographic Research and IRES Piedmont, for supporting this research. Maria Cristina Migliore and Moreno Demaria were so kind to spend time and efforts in promoting the idea of studying fertility in Turin and preparing the data. I am also grateful for advice and suggestions from Francesco Billari and Gianpiero Dalla Zuanna. Thank also to Gunnar Andersson, Pau Baizan and Hill Kulu; who were so patient to read my work, and thanks in particular to Lucia Coppola with whom I shared months of Rostock and research experience.

Finally, I am glad to Yvonne Sandor and Susann Baker for editing my English. 


\section{References}

Abbasi-Shavazi M. J., McDonald, P., 2000. Fertility and multiculturalism: immigrant fertility in Australia, 1977-1991, International Migration Review, Vol. 34, No.1, pp. 215-242.

Abbasi-Shavazi M. J., McDonald, P., forthcoming. A comparison of fertility patterns of European immigrants in Australia with those in the country of origin, Genus.

Andersson G., 2001. Childbearing patterns of foreign-born women in Sweden, MPIDR Working Paper WP2001-011, http://www.demogr.mpg.de/, Max Planck Institute for Demographic Research, Rostock, Germany.

Astone N. M., Nathanson C. A., Schoen R. and Kim Y. J., 1999. Family demography, social theory, and investment in social capital, Population and Development Review, Vol. 25, No.1 (Mar.), pp. 1-31.

Baizan P., 2002. Formation des ménages et migrations: analyse biographique de trois générations espagnoles, Louvain-la-Neuve: Bruylant-Academia. Série Démographie, 16.

Bean F.D. and Swicegood G., 1985. Mexican American fertility patterns. Austin: University of Texas Press.

Becker G. S., 1981. A Treatise on the Family. Cambridge: Harvard University Press.

Berry B.J.L. (Ed.), 1976. Urbanization and Counterurbanization. Beverly Hills: Sage Publications. 
Billari F.C., 2001.The analysis of early life courses: complex descriptions of the transition to adulthood, Journal of Population Research, Vol. 18, No. 2, pp. 119-142.

Billari F.C., Dalla Zuanna G., Demaria M., Migliore M.C., 1999. Un record linkage per studiare la fecondità delle donne residenti a Torino fra il 1970 e il 1994, in Società Italiana di Statistica, Atti della XXXIX Riunione Scientifica, Istituto di Statistica e Matematica, Istituto Universitario Navale, Napoli, pp. 535-542.

Billari F. C., Castiglioni M., Castro Martìn T., Michielin F. and Ongaro F. (forthcoming), Household and Union Formation in a Mediterranean Fashion: Italy and Spain. In E. Klijzing and M. Corijn (Eds.). Comparative research on fertility and the family in contemporary Europe: findings and lessons. New York/Geneva: United Nations.

Blossfeld H.-P. and De Rose A., 1992. Educational expansion and changes in entry into marriage and motherhood. The experience of Italian women, Genus, Vol. 48, pp. 73-89.

Blossfeld H.-P. and Huinink J., 1991. Human Capital Investments or Norms of Role Transition? How Women's Schooling and Career Affect the Process of Family Formation, American Journal of Sociology, Vol. 97, No. 1. (Jul.), pp. 143-168.

Blumen I., Kogan M. and McCarthy P. J., 1955. The industrial mobility of labor as a probability process. Cornell Studies of Industrial and Labor Relations, No. 6 Ithaca, N.Y.: Cornell University Press.

Bogue D. J., 1955. Urbanism in the United States. American Journal of Sociology, Vol. 60, Issue 5, World Urbanism (Mar.), pp. 471-486. 
Bonifazi C. and Heins F., 2000. Long-term trends of internal migration in Italy. International Journal of Population Geography, Vol. 6, pp. 111-131.

Boongarts J. and Feeney G., 1998. On the quantum and tempo fertility. Population and Development Review Vol. 24, No. 2, pp. 271-291.

Carlson E. D., 1985. The impact of international migration upon the timing of marriage and childbearing, Demography, Vol. 22, No. 1, pp.61-72.

Castiglioni M. and Dalla Zuanna G., 1994. Innovation and tradition: reproductive and marital behavior in Italy in the 1970s and 1980s, European Journal of Population, Vol. 10, pp. 107-141.

Coppola L., 2002. Schooling and household formation as simultaneous processes: Italy and Spain. Paper presented at ESPE 2002, Bilbao.

Costa G. and Demaria M., 1988. Un sistema longitudinale di sorveglianza della mortalità secondo le caratteristiche socio-economiche, come rilevate ai censimenti di popolazione: descrizione e documentazione del sistema. Epidemiologia e Prevenzione Vol. 10, pp. 37-47.

Costa G., Cadum E. and Demaria M., 1994. La mortalità e le differenze sociali a Torino. In: D'ambrosio R. and Segnan N. (eds.): Schegge di salute. Torino.

Courgeau D., 1984. Relations between life cycle and migration. Population, Vol. 39, pp. 483-513.

Courgeau D., 1989. Family Formation and Urbanization, Population: an English Selection, Vol. 44, No. 1. (Sep.), pp. 123-146. 
Dalla Zuanna G., 2001. The banquet of Aeolus: a familistic interpretation of Italy's lowest low fertility, Demographic Research, Vol. 4, No. 5, pp. 133-162.

Da Vanzo, 1981. Microeconomic approaches to studying migration decision. In: De Jong G.F. and Gardner (eds.): Migration decision making. Multidisciplinary approaches to microlevel studies in developed and developing countries. New York. Pergamon Press.

Davis R. B., Crouchley R., Pickles A. R., 1982. Modelling the evolution of heterogeneity in residential mobility, Demography, Vol. 19, No. 3 (Aug.), pp. 291299.

Flöthmann J. E., 1993. Migration and the life course, Bulletin de Méthodologie Sociologique, Vol. 39, pp. 45-58.

Ford K., 1990. Duration of residence in the United States and the fertility of U.S. immigrants, International Migration Review, Vol. 24, No. 1, pp. 34-68.

Frey W. H. and Kobrin F. E., 1982. Changing families and changing mobility: their impact on the central city, Demography, Vol. 19, No. 3 (Aug.), pp. 261-277.

Frey W. H. and Speare A. Jr., 1992. The revival of metropolitan population growth in the United States: an assessment of findings from the 1990 Census, Population and Development Review, Vol. 18, No. 1 (Mar.), pp. 129-146.

Gini C., 1924. Premiers Recherches sur la Fécondabilité de la Femme, Proceedings of International Mathematic Congress, 2:889-992.

Goldstein S. 1973. Interrelation between migration and fertility in Thailand, Demography, Vol. 10, No. 2, pp. 225-241. 
Goldstein S. and Goldstein A., 1983. Migration and fertility in Peninsular Malaysia: an analysis using life history data. Santa Monica: Rand Corporation Report No. N1860-AID.

Grundy E., 1986. Migration and fertility behaviour in England and Wales: a record linkage study. Journal of Biosocial Science, Vol. 18, pp. 403-423.

Grundy E.M.D. and Fox A.J., 1985. Migration during early married life. European Journal of Population, Vol. 1, pp. 237-263.

Heckman J. J. and Walker J. R., 1992. Understanding Third Births in Sweden. In: Trussell J.; Hankinson R.; Tilton J. (eds.): Demographic Applications of Event History Analysis. Oxford: Clarendon Press, pp. 157-208.

Hervitz, H. M.,1985. Selectivity, Adaptation, or Disruption? A Comparison of Alternative Hypotheses on the Effects of Migration on Fertility: The Case of Brazil. International Migration Review, Vol. 19, No. 2. (Summer), pp. 293-317.

Hoem B., Hoem J.M., 1989. The Impact of Women's Employment on Second and Third Births in Modern Sweden, Population Studies, Vol. 43, No. 1 (Mar.), pp. 47-67.

IRES, 1994. Le trasformazioni demografiche della popolazione di Torino e dell'area metropolitana. In: D’Ambrosio R. and Segnan N. (eds.): Schegge di salute. Torino.

Kahn J. R., 1994. Immigrant and native fertility during the 1980s: adaptation and expectations for the future, International Migration Review, Vol. 28, No. 3, pp. 501519.

Kohler H.-P., Billari F. C., Ortega J. A., 2001. Towards a Theory of Lowest-Low Fertility. MPIDR working paper WP 2001-032. 
Kravdal O., 1992. The Emergence of a Positive Relation between Education and Third Birth Rates in Norway with Supportive Evidence from the United States, Population Studies, Vol. 46, No. 3. (Nov.), pp. 459-475.

Kravdal O., 2001. The high fertility of college educated women in Norway: an artifact of the separate modelling of each parity transition, Demographic Research, Vol. 5, No. 6, pp.187-215.

Landale N. S. and Guest A. M., 1985. Constraints, satisfaction and residential mobility: Speare's model reconsidered, Demography, Vol. 22, No. 2 (May), pp.199222.

Lee E. S., 1966. Theory of Migration, Demography, Vol. 3, No. 1. pp. 47-57.

Liefbroer AC, Corijn M, 1999. Who, what, where, and when? Specifying the impact of educational attainment and labour force participation on family formation, European Journal of Population, Vol. 15, No.1. (Mar.), pp. 45-75.

Lillard, L. A., 1993. Simultaneous Equations for Hazards: Marriage Duration and Fertility Timing, Journal of Econometrics, 56, pp. 189-217.

Lillard, L. A. and Panis C. W. A., 2000. aML user's guide and reference manual.

Lillard L. A. and Waite L.J., 1993. A joint model of marital childbearing and marital disruption, Demography, Vol. 30, No. 4 (Nov.), pp. 653-681.

Long L.H., 1972. The Influence of Number and Ages of Children on Residential Mobility, Demography, Vol. 9, No. 3. (Aug.), pp. 371-382. 
Long L.H., 1974. Women's Labor Force Participation and the Residential Mobility of Families, Social Forces, Vol. 52, No. 3. (Mar.), pp. 342-348.

Marini M. M., 1981. Effects of the timing of marriage and first birth on fertility. Journal of the Marriage and the Family, Vol. 43, No. 1 (Feb.), pp. 27-46.

Marini M. M., 1984. Women's Educational Attainment and the Timing of Entry into Parenthood, American Sociological Review, Vol. 49, No. 4. (Aug.), pp. 491-511.

Martinotti G., 1993. Metropoli. La nuova morfologia sociale della città, il Mulino, Bologna.

McAuley W. J. and Nutty C. L., 1982. Residential preferences and moving behavior: a family life-cycle analysis, Journal of Marriage and the Family, Vol. 44, No. 2 (May), pp. 301-309.

Mincer J., 1978. Family Migration Decisions, The Journal of Political Economy, Vol. 86, No. 5. (Oct.), pp. 749-773.

Morris E. W., Crull S. R. and Winter M., 1976. Housing norms, housing satisfaction and the propensity to move, Journal of Marriage and the Family, Vol. 38, No. 2 (May), pp. 309-320.

Mulder C., 1993. Migration Dynamics: A Life Course Approach. Amsterdam: Thesis Publishers.

Mulder C. and Wagner M.,1993. Migration and marriage in the life course: a method for studying synchronized events, European Journal of Population, Vol. 9, pp. 55-76. 
Mulder C. and Hoomeijer, 1999. Residential relocations in the life course. In: Leo J. G. van Wissen; Dykstra, Pearl A.(Eds.) Population Issues: an Interdisciplinary Focus. New York: Kluwer Academic / Plenum Publishers.

Mulder C. and Wagner M., 2001. The connections between family formation and first-time ownership in the context of West Germany and the Netherlands, European Journal of Population, Vol. 17, pp. 137-164.

Murphy M., 1992. The progression to the third birth in Sweden. In: Trussell J.; Hankinson R.; Tilton J. (eds.): Demographic Applications of Event History Analysis. Oxford: Clarendon Press, pp. 141-156.

Murphy M. J. and Sullivan, 1985. Housing tenure and family formation in contemporary Britain, European Sociological Review, Vol. 1, pp. 230-243.

Ongaro F., 2002. La bassa fecondità in Italia tra fattori esplicativi e implicazioni socio-economiche: conseguenze per la ricerca. Paper presented at XLI Riunione Scientifica della Società Italiana di Statistica, Milano 5-7 Giugno 2002.

Raftery A. E., 1995. Bayesian model selection in social research. Sociological Methodology, Vol. 25, pp. 111-163.

Rodriguez, G., Hobcraft, J. N., McDonald, J. W., Menken, J. and Trussell, J., 1984. Comparative analysis of determinants of birth intervals, World Fertility Survey Comparative Studies N0. 30 (International Statistical Institute, Voorburg).

Rosenzweig M. R. and Wolpin K. I., 1980. Life-Cycle Labor Supply and Fertility: Causal Inferences from Household Models, The Journal of Political Economy, Vol. 88, No. 2. (Apr.), pp. 328-348. 
Rosina A., 2001. Analisi delle storie riproduttive. Metodologia e applicazioni a dati italiani, CLEUP editrice, Padova.

Sabagh G., Van Arsdol M.D., Butler E.W., 1969. Some determinants of metropolitan residential mobility: conceptual considerations, Social Forces, Vol. 48, No. 1 (Sep.), pp. 88-98.

Sandefur G.D. and Scott W.J., 1981. A dynamic analysis of migration: an assessment of the effects of age, family and career variables, Demography, Vol. 18, No. 3. (Aug.), pp. 355-368.

South S. J. and Crowder K. D., 1997. Residential mobility between cities and suburbs: race, sub-urbanization, and back-to-the-city moves, Demography, Vol. 34, No. 4 (Nov.), pp. 525-538.

Speare A. Jr., 1974. Residential Satisfaction as an Intervening Variable in Residential Mobility, Demography, Vol. 11, No. 2. (May), pp. 173-188.

Stark O., 1991. The migration of labor. Cambridge, MA: Baxil Blackwell.

Spilerman S., 1972. Extensions of the mover-stayer model, American Journal of Sociology, Vol.78, No.3 (Nov.), pp. 599-626.

Standberg M. and Hoem J. M., 2002. Patterns of twinning for Swedish women, 19611999, MPIDR Working Paper WP2002-031, http://www.demogr.mpg.de/, Max Planck Institute for Demographic Research, Rostock, Germany.

Stephen E. H. and Bean F. D., 1992. Assimilation, disruption and the fertility of Mexican-origin women in the United States, International migration review, Vol. 26, No. 1, pp. 67-88. 
United Nations, 1980. Patterns of urban and rural population growth, Department of International Economic. New York: United Nations.

Ware H., 1975. Immigrant fertility: behaviour and attitudes. International Migration Review, Vol. 9, No. 3, pp. 361-378.

Yamaguchi K. and Ferguson L.R., 1995. The Stopping and Spacing of Childbirths and Their Birth-History Predictors: Rational-Choice Theory and Event-History Analysis, American Sociological Review, Vol. 60, No. 2. (Apr.), pp. 272-298.

Yapa L., Polese M. and Wolpert J., 1971. Interdependencies of Commuting, Migration, and Job Site Relocation, Economic Geography, Vol. 47, No. 1, Perspectives on Urban Spatial Systems. (Jan.), pp. 59-72.

Zarate A. and de Zarate A., 1975. On the Reconciliation of Research Findings of Migrant-Nonmigrant Fertility Differentials in Urban Areas. International Migration Review, Vol. 9, No. 2, Migration and Fertility (Summer), pp. 115-156.

Zukin S., 1987. Gentrification: culture and capital in the urban core, Annual Review of Sociology, Vol. 13, pp. 129-147. 
Fig. 1. The processes under study

\section{Fertility}

process

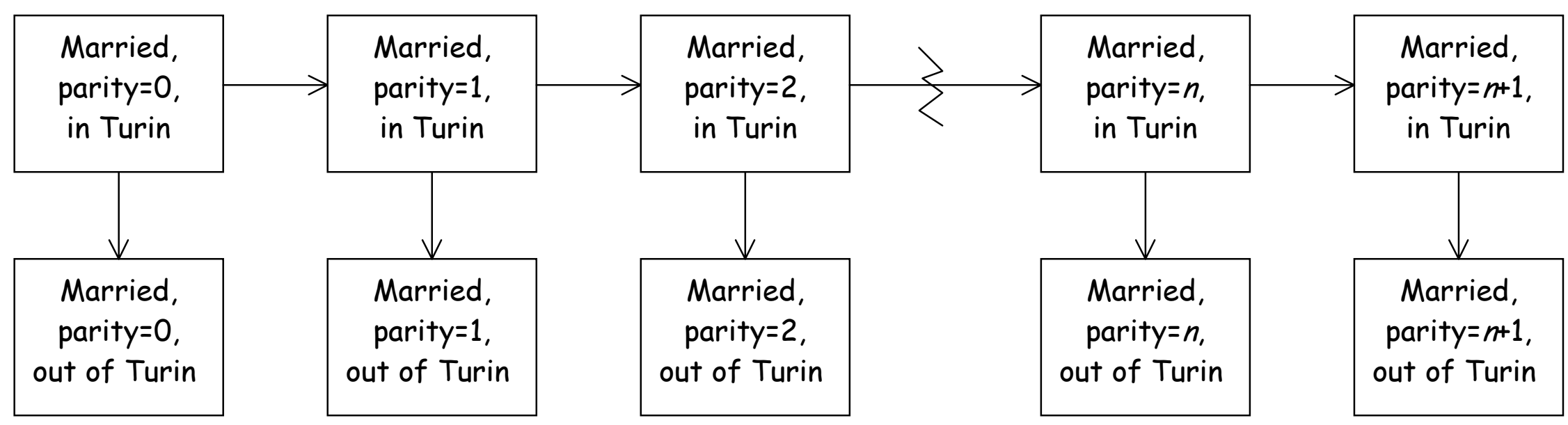

\section{Migration}

process 
Fig. 2. Baseline risks for fertility process by order of birth.

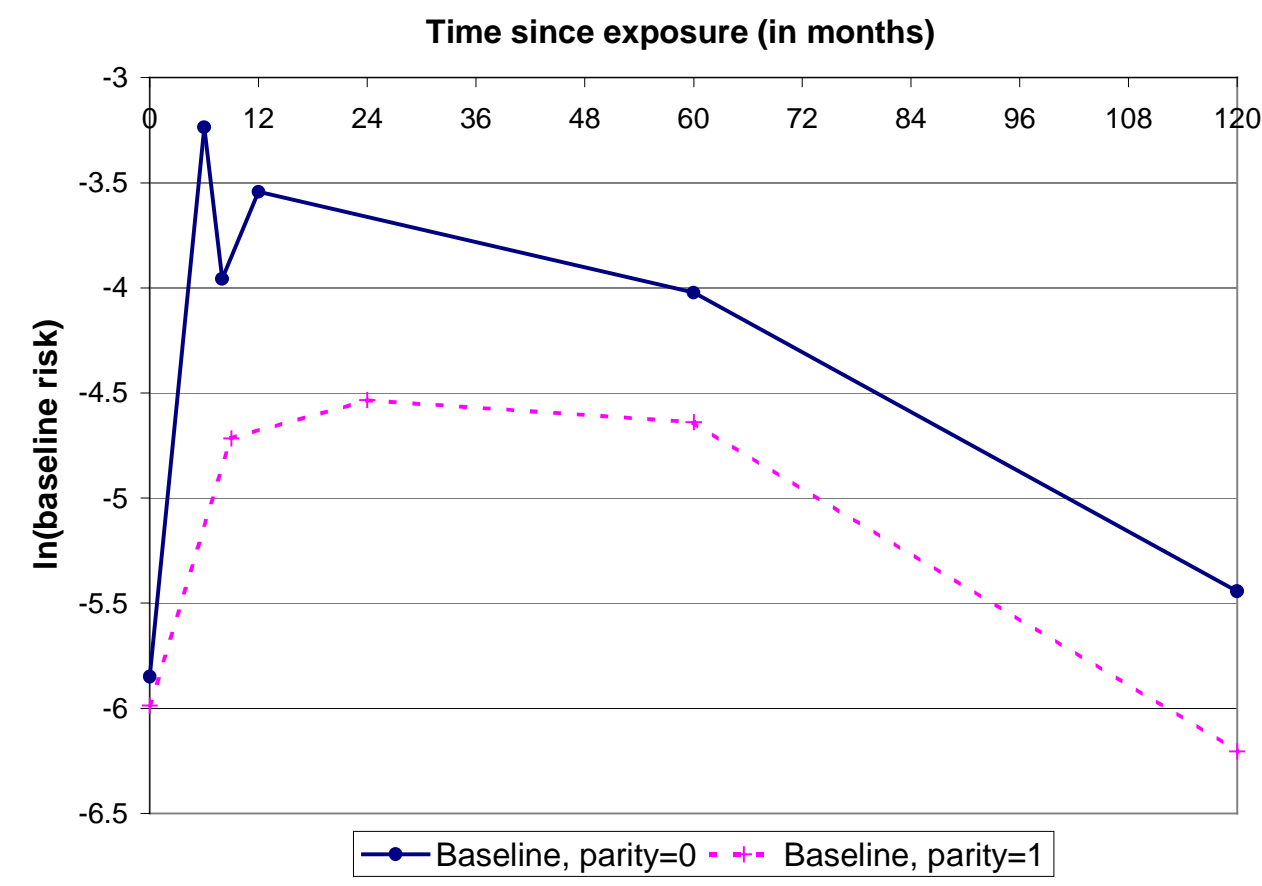

Fig. 3. Baselines risks for migration process.

Time since exposure (in months)

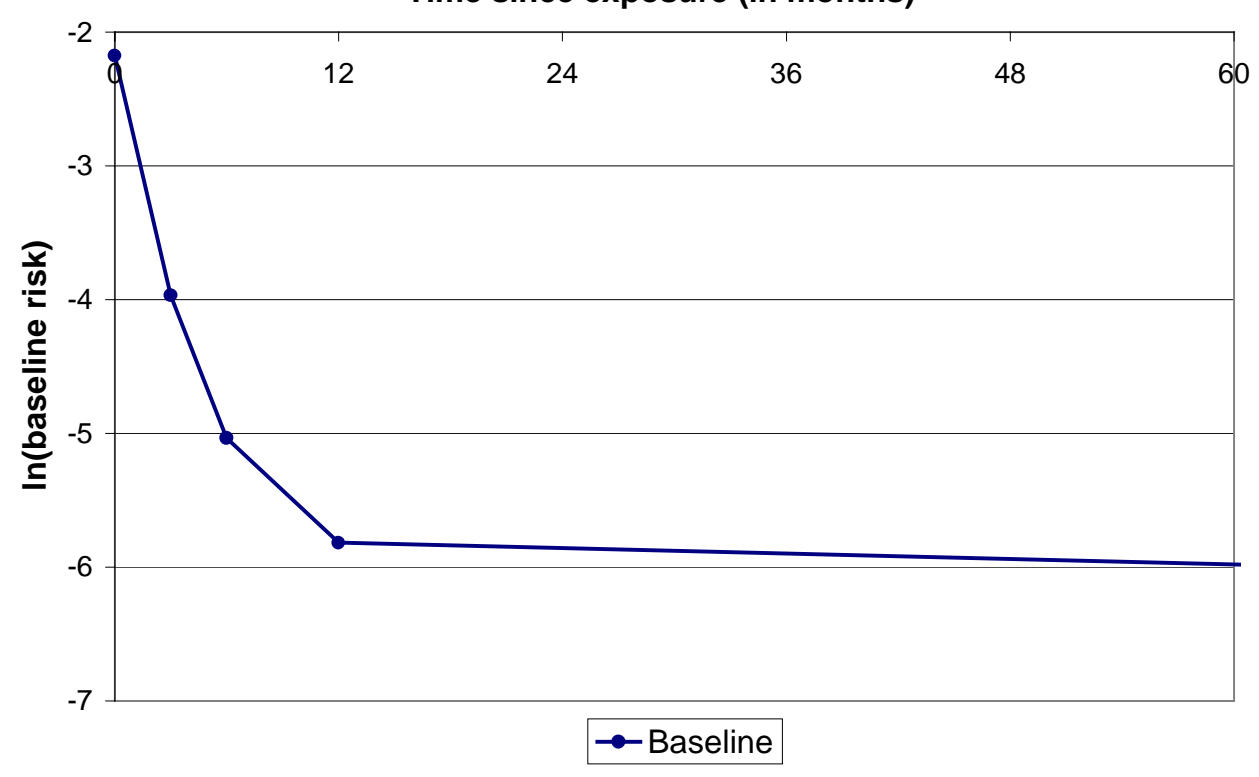


Table 1. Results for fertility model

\begin{tabular}{|c|c|c|c|c|c|c|}
\hline \multirow{2}{*}{+2} & \multicolumn{2}{|c|}{ Model 1} & \multicolumn{2}{|c|}{ Model 2} & \multicolumn{2}{|c|}{ Model 3} \\
\hline & Estimate & s.e. & Estimate & s.e. & Estimate & s.e. \\
\hline \multicolumn{7}{|c|}{ Current parity (ref.: parity $=1$ ) } \\
\hline Parity $=2$ & $-1.5424^{\star * \star}$ & $(0.0517)$ & 0.0583 & $(0.2114)$ & -0.1135 & $(0.2253)$ \\
\hline Parity $=3$ & $-1.6436 * * *$ & $(0.1511)$ & 0.2435 & $(0.3776)$ & -0.2003 & $(0.3978)$ \\
\hline \multicolumn{7}{|c|}{ Age at marriage (regressor spline for 1st birth) } \\
\hline Slope age $15-23$ & & & $-0.0137^{\star * \star}$ & $(0.0009)$ & $-0.0160^{* * *}$ & $(0.0011)$ \\
\hline Slope age $23-26$ & & & 0.0025 * & $(0.0014)$ & 0.0028 * & $(0.0015)$ \\
\hline Slope age >26 & & & $-0.0043^{* * *}$ & $(0.0007)$ & $-0.0043^{* * *}$ & $(0.0008)$ \\
\hline
\end{tabular}

Age at previous birth (regressor spline, no knots)

\begin{tabular}{|c|c|c|c|c|c|}
\hline & $-0.0034^{* * *}$ & $(0.0005)$ & $-0.0043^{* * *}$ & $(0.0005)$ \\
\hline \multicolumn{2}{|c|}{ Effect of age at $2^{\text {nd }}$ birth on $3^{\text {rd }}$ birth } & $-0.0088^{* * *}$ & $(0.0010)$ & $-0.0085^{\star * *}$ & $(0.0010)$ \\
\hline \multicolumn{6}{|c|}{ Length of previous interval (regressor spline) } \\
\hline $\begin{array}{l}\text { Marriage- } \\
1^{\text {st }} \text { birth }\end{array}$ & $<12$ months & $0.0435^{* * *}$ & $(0.0129)$ & $0.0621^{\star * *}$ & $(0.0149)$ \\
\hline Previous births & Slope & $-0.0182^{* * *}$ & $(0.0027)$ & $-0.0166^{* * *}$ & $(0.0028)$ \\
\hline
\end{tabular}

Being immigrated or not (ref.: not immigrant) (int. with parity)

\begin{tabular}{lllll}
\hline Being immigrated, no children & $0.2530^{* * *}$ & $(0.0308)$ & $0.2963^{* * *}$ & $(0.0363)$ \\
\hline Being immigrated, one child & $0.1558^{* * *}$ & $(0.0425)$ & $0.1972^{* * *}$ & $(0.0467)$ \\
\hline Being immigrated, two children & 0.0482 & $(0.1076)$ & 0.0989 & $(0.1117)$ \\
\hline Being immigrated, higher parity & -0.2671 & $(0.3320)$ & -0.1939 & $(0.3282)$
\end{tabular}

Twins as last parity (ref.: no twins)

\begin{tabular}{lllll}
\hline Twins=yes & -0.4504 & $(0.2800)$ & -0.2857 & $(0.2917)$
\end{tabular}

Educational level (ref.: low) (int. with parity)

\begin{tabular}{c|lcccc}
\hline \multirow{2}{*}{ Parity $=0$} & Medium level & $-0.2728^{* * *}$ & $(0.0499)$ & $-0.3063^{* * *}$ & $(0.0545)$ \\
& High level & $-0.2885^{* * *}$ & $(0.0666)$ & $-0.3404^{* * *}$ & $(0.0749)$ \\
\hline \multirow{2}{*}{ Parity=1 } & Medium level & $-0.2582^{* * *}$ & $(0.0519)$ & $-0.3231^{* * *}$ & $(0.0588)$ \\
& High level & $0.3458^{* * *}$ & $(0.0864)$ & $0.3302^{* * *}$ & $(0.0943)$ \\
\hline \multirow{2}{*}{ Parity $=2$} & Medium level & -0.0351 & $(0.1241)$ & -0.1154 & $(0.1305)$ \\
& High level & $0.5247^{* *}$ & $(0.2180)$ & $0.4615^{* *}$ & $(0.2248)$ \\
\hline \multirow{2}{*}{ Parity $>2$} & Medium level & -0.3221 & $(0.2934)$ & -0.3794 & $(0.2923)$ \\
& High level & -0.7399 & $(0.6496)$ & -0.7596 & $(0.6478)$
\end{tabular}

Variance of the heterogeneity component

$\begin{array}{ll}\text { Sigma-fertility } & 0.4747^{* * *}(0.0582)\end{array}$

\begin{tabular}{cccc}
\hline $\mathrm{Ln}-\mathrm{L}$ & -66978.6 & -66114.2 & -66100.9 \\
\hline
\end{tabular}

NOTE: Asymptotic standard errors in parentheses; significance: '*'=10\%; '**' $=5 \%$; '***' $=1 \%$. 
Table 2. Results for out migration model

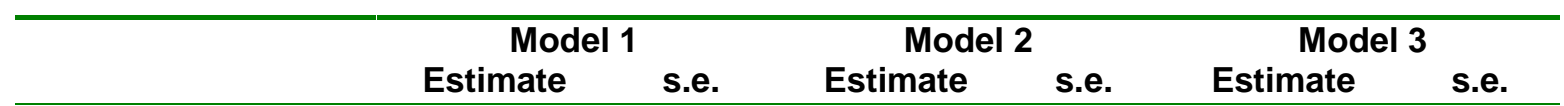

Current parity (ref.: parity $=0$ )

\begin{tabular}{lllllll}
\hline Parity $=1$ & $-0.1175^{* *}$ & $(0.0548)$ & $-0.1138^{* *}$ & $(0.0558)$ & $-0.12266^{* *}$ & $(0.0580)$ \\
Parity $=2$ & -0.1082 & $(0.0672)$ & -0.0463 & $(0.0733)$ & -0.0545 & $(0.0773)$ \\
Parity $>2$ & 0.0209 & $(0.1135)$ & 0.0921 & $(0.1198)$ & 0.0961 & $(0.1287)$
\end{tabular}

Current age of the woman (duration spline)

$\begin{array}{lllllll}\text { Slope age 15-17 } & 0.0791^{* * *}(0.0297) & 0.0798^{* * *} & (0.0291) & 0.0814^{* * *} & (0.0296) \\ \text { Slope age 17-30 } & 0.0001^{* * *} & (0.0005) & 0.0022^{* *} & (0.0005) & 0.0026^{* *} & (0.0006) \\ \text { Slope age 30-40 } & -0.0048^{* * *} & (0.0008) & -0.0032^{* * *} & (0.0008) & -0.0031^{* * *} & (0.0008) \\ \text { Slope age }>40 & -0.0107^{* * *} & (0.0025) & -0.0105^{* * *} & (0.0026) & -0.0112^{* * *} & (0.0026)\end{array}$

Having school aged children (ref.: no)

Having school aged children

$-0.1811^{* * *}(0.0655) \quad-0.1857^{* * *}(0.0662)$

Educational level (ref.: low)

\begin{tabular}{lllll}
\hline Medium level & $-0.3884^{* * *}$ & $(0.0477)$ & $-0.4489^{* * *}$ & $(0.0567)$ \\
High level & $-1.5051^{* * *}$ & $(0.0992)$ & $-1.7008^{* * *}$ & $(0.1204)$
\end{tabular}

Provenience of immigration (ref.: non immigrated)

\begin{tabular}{|c|c|c|c|c|}
\hline Turin province & 0.0797 & $(0.0598)$ & 0.0827 & $(0.0688)$ \\
\hline North-Centre Italy & $0.1173^{* *}$ & $(0.0528)$ & $0.1322 * *$ & $(0.0614)$ \\
\hline South Italy & $-0.1511^{\star \star \star}$ & $(0.0426)$ & $-0.1880 * * *$ & $(0.0512)$ \\
\hline Foreign countries & 0.1220 & $(0.1204)$ & 0.1277 & $(0.1391)$ \\
\hline \multicolumn{5}{|c|}{ Variance of the heterogeneity component } \\
\hline Sigma-out-migration & & & $0.7145^{* * *}$ & $(0.1088)$ \\
\hline
\end{tabular}

NOTE: Asymptotic standard errors in parentheses; significance: ${ }^{* *}=10 \% ;{ }^{\prime * * *}=5 \%$; ${ }^{\prime * * * \prime}=1 \%$. 
Table 3. Results for out migration model when we distinguish by destination

\begin{tabular}{|c|c|c|c|c|}
\hline \multirow[t]{2}{*}{ Destination: } & \multicolumn{2}{|c|}{ Turin province } & \multicolumn{2}{|c|}{ Other destinations } \\
\hline & Estimate & s.e. & Estimate & s.e. \\
\hline \multicolumn{5}{|l|}{ Current parity (ref.: parity=0) } \\
\hline Parity $=1$ & -0.0892 & $(0.0690)$ & $-0.2091 *$ & $(0.1069)$ \\
\hline Parity $=2$ & -0.0567 & $(0.0892)$ & -0.0218 & $(0.1526)$ \\
\hline Parity $>2$ & 0.0774 & $(0.1443)$ & 0.1800 & $(0.2735)$ \\
\hline \multicolumn{5}{|l|}{ Current age of the woman (duration spline) } \\
\hline Slope age $15-17$ & $0.0875 * *$ & $(0.0392)$ & 0.0749 & $(0.0462)$ \\
\hline Slope age $17-30$ & $0.0041^{* * *}$ & $(0.0007)$ & -0.0011 & $(0.0010)$ \\
\hline Slope age $30-40$ & $-0.0046 * * *$ & $(0.0009)$ & 0.0013 & $(0.0015)$ \\
\hline Slope age $>40$ & $-0.0108 * * *$ & $(0.0029)$ & $-0.0124 * *$ & $(0.0055)$ \\
\hline \multicolumn{5}{|l|}{ Having school aged children (ref.: no) } \\
\hline Having school aged children & $-0.1556^{* *}$ & $(0.0742)$ & -0.3234 ** & $(0.1462)$ \\
\hline \multicolumn{5}{|l|}{ Educational level (ref.: low) } \\
\hline Medium level & $-0.4214^{\star * *}$ & $(0.0684)$ & $-0.4815^{* * *}$ & $(0.0958)$ \\
\hline High level & $-1.7403^{* * *}$ & $(0.1443)$ & $-1.4920 * * *$ & $(0.1975)$ \\
\hline \multicolumn{5}{|c|}{ Provenience of immigration (ref.: non immigrated) } \\
\hline Turin province & $0.1766^{* *}$ & $(0.0784)$ & -0.1936 & $(0.1356)$ \\
\hline North-Centre Italy & 0.0332 & $(0.0725)$ & $0.3366^{* * *}$ & $(0.1100)$ \\
\hline South Italy & $-0.1891^{* * *}$ & $(0.0600)$ & $-0.1764 *$ & $(0.0902)$ \\
\hline Foreign countries & $0.2715^{*}$ & $(0.1596)$ & -0.3137 & $(0.2947)$ \\
\hline \multicolumn{5}{|l|}{ Variance of the heterogeneity component } \\
\hline Sigma-out-migration & $0.7930^{* \star *}$ & $(0.1332)$ & $0.8693^{* * *}$ & $(0.3155)$ \\
\hline Ln-L & -23902 & 2.3 & -9501 & \\
\hline
\end{tabular}

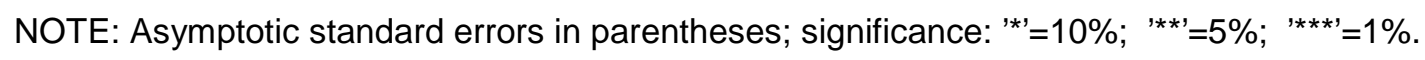


Table 4. Results for the model with correlated unobserved heterogeneity terms

\begin{tabular}{lcc}
\hline \multicolumn{1}{c}{ Fertility } & Estimate & s.e. \\
\hline \multicolumn{3}{c}{} \\
Current parity (ref.: parity=1) & \\
\hline Parity=2 & -0.1153 & $(0.2254)$ \\
Parity=3 & -0.2088 & $(0.3984)$ \\
& & \\
Age at marriage & $-0.0161^{\star * *}$ & $(0.0011)$ \\
\hline Slope age 15-23 & $0.0028^{*}$ & $(0.0015)$ \\
Slope age 23-26 & $-0.0043^{* * *}$ & $(0.0008)$ \\
Slope age $>26$ & & \\
& & \\
Age at previous birth & $-0.0043^{* * *}$ & $(0.0005)$ \\
\hline Age at $1^{\text {st }}$ birth & $-0.0085^{* * *}$ & $(0.0010)$
\end{tabular}

\begin{tabular}{lll} 
Migration & Estimate & s.e. \\
\hline
\end{tabular}

Current parity (ref.: parity $=0$ )

\begin{tabular}{lll}
\hline Parity $=1$ & -0.0641 & $(0.0751)$ \\
Parity $=2$ & 0.0665 & $(0.1276)$ \\
Parity $>2$ & 0.2836 & $(0.2008)$
\end{tabular}

\section{Current age of the woman}

\begin{tabular}{lrl}
\hline Slope age 15-17 & $0.0819^{* * *}$ & $(0.0298)$ \\
Slope age 17-30 & $0.0026^{* * *}$ & $(0.0006)$ \\
Slope age $30-40$ & $-0.0029^{* * *}$ & $(0.0008)$ \\
Slope age $>40$ & $-0.0106^{* * *}$ & $(0.0026)$
\end{tabular}

Having school aged children (ref.: no)

School aged children $\quad-0.1782^{* * *}(0.0666)$

\section{Length of previous interval0.0010}

\begin{tabular}{c|lrl} 
Protogenesic & $<12 \mathrm{~m}$ & $0.0622^{\star * *}$ & $(0.0149)$ \\
& $>12 \mathrm{~m}$ & $-0.0073^{* \star *}$ & $(0.0016)$ \\
\hline Intergenesic & Slope & $-0.0166^{* * *}$ & $(0.0028)$
\end{tabular}

Educational level (ref.: low)

\begin{tabular}{lll}
\hline Medium level & $-0.4419^{* * *}$ & $(0.0580)$ \\
High level & $-1.7063^{* * *}$ & $(0.1205)$
\end{tabular}

Being immigrated (ref.: not immigrant)

\begin{tabular}{|c|c|c|}
\hline Immigrant, parity $=0$ & $0.2985^{* * *}$ & $(0.0365)$ \\
\hline Immigrant, parity=1 & $0.1998^{* * *}$ & $(0.0468)$ \\
\hline Immigrant, parity=2 & 0.1040 & $(0.1119)$ \\
\hline Immigrant, parity $>2$ & -0.1914 & $(0.3283)$ \\
\hline
\end{tabular}

Provenience of immigration (ref.: non imm.)

\begin{tabular}{lcc}
\hline Turin province & 0.0757 & $(0.0699)$ \\
North-Centre Italy & $0.1196{ }^{*}$ & $(0.0641)$ \\
South Italy & $-0.1922^{* * *}$ & $(0.0512)$ \\
Foreign country & 0.1237 & $(0.1402)$ \\
\hline
\end{tabular}

Twins as last parity (ref.: no twins)

\begin{tabular}{|c|c|c|c|}
\hline \multicolumn{2}{|c|}{ Twins=yes } & -0.2774 & $(0.2904)$ \\
\hline \multicolumn{4}{|c|}{ Educational level (ref.: low) } \\
\hline 0 & Medium level & $-0.3028^{* * *}$ & $(0.0548)$ \\
\hline child & High level & $-0.3210^{* * *}$ & $(0.0774)$ \\
\hline 1 & Medium level & $-0.3182^{* * *}$ & $(0.0589)$ \\
\hline child & High level & $0.3525^{* * *}$ & $(0.0961)$ \\
\hline 2 & Medium level & -0.1080 & $(0.1307)$ \\
\hline childr. & High level & 0.4893 ** & $(0.2262)$ \\
\hline$>2$ & Medium level & -0.3665 & $(0.2919)$ \\
\hline Childr. & High level & -0.7296 & $(0.6490)$ \\
\hline
\end{tabular}

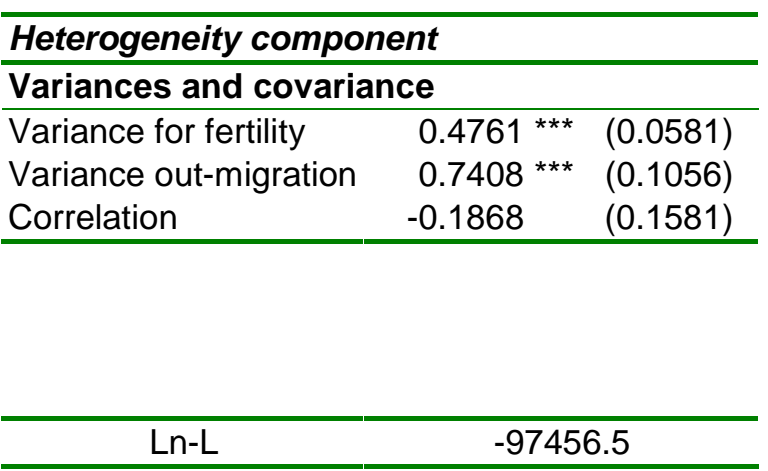

NOTE: Asymptotic standard errors in parentheses; significance: '*' $=10 \%$; '**' $=5 \%$; ${ }^{* * \star *}=1 \%$. 